\title{
Phytochrome Mediated Responses in Agrobacterium fabrum: Growth, Motility and Plant Infection
}

\author{
Peng Xue ${ }^{1,4} \cdot$ Yingnan Bai $^{1,6} \cdot$ Gregor Rottwinkel $^{1} \cdot$ Elizaveta Averbukh $^{1} \cdot{\text { Yuanyuan } \mathrm{Ma}^{2}}^{2}$. Thomas Roeder ${ }^{2,3}$. \\ Patrick Scheerer ${ }^{5} \cdot$ Norbert Krauß $^{1} \cdot$ Tilman Lamparter $^{1}$ (D)
}

Received: 30 October 2020 / Accepted: 28 April 2021 / Published online: 22 May 2021

(c) The Author(s) 2021

\begin{abstract}
The soil bacterium and plant pathogen Agrobacterium fabrum C58 has two phytochrome photoreceptors, Agp1 and Agp2. We found that plant infection and tumor induction by A. fabrum is down-regulated by light and that phytochrome knockout mutants of A. fabrum have diminished infection rates. The regulation pattern of infection matches with that of bacterial conjugation reported earlier, suggesting similar regulatory mechanisms. In the regulation of conjugation and plant infection, phytochromes are active in darkness. This is a major difference to plant phytochromes, which are typically active after irradiation. We also found that propagation and motility were affected in agp $1^{-}$and agp $2^{-}$knockout mutants, although propagation was not always affected by light. The regulatory patterns can partially but not completely be explained by modulated histidine kinase activities of Agp1 and Agp2. In a mass spectrometry-based proteomic study, 24 proteins were different between light and dark grown A. fabrum, whereas 382 proteins differed between wild type and phytochrome knockout mutants, pointing again to light independent roles of Agp1 and Agp2.
\end{abstract}

\section{Introduction}

Soil bacteria of the genus Agrobacterium can transfer genes into plants and thereby induce the formation of plant tumors. This infection causes massive losses in agriculture, but the mechanism is on the other hand used for plant transformation in many research laboratories [1]. Tumor formation is

Tilman Lamparter

Tilman.lamparter@kit.edu

1 Botanical Institute, Karlsruhe Institute of Technology, 76131 Karlsruhe, Germany

2 Zoological Institute, Molecular Physiology, Kiel University, Olshausenstrasse 40, 24098 Kiel, Germany

3 German Center for Lung Research (DZL, Airway Research Center North), Kiel, Germany

4 Present Address: Michael Smith Laboratories, Department of Microbiology and Immunology, University of British Columbia, Vancouver, BC, Canada

5 Institute of Medical Physics and Biophysics, Group Protein X-Ray Crystallography and Signal Transduction, Freie Universität Berlin and Humboldt-Universität Zu Berlin , Charité-Universitätsmedizin, Berlin, Germany

6 Present Address: West China Hospital, Sichuan University, Chengdu 610054, China dependent on the presence of a tumor inducing plasmid, the Ti-plasmid. The infection process starts with the excision of a single stranded sequence termed T-DNA from the Tiplasmid. This T-DNA is transferred to the plant cell, where it is randomly inserted into the plant genome and where it induces the synthesis of auxin and cytokinin. These phytohormones stimulate tumor growth. The infected cells produce amino acid derivatives, opines, which are exported in the soil and can be used by A. fabrum for nutrition [2]. The entire virulence and infection process is induced by plant exudates such as acetosyringone; other environmental stimuli such as light are so far unknown. A. fabrum is known as soil bacterium [3] and it was long anticipated that it does not respond to light. However, sunlight penetrates several millimeters deep into the soil [4], and plant roots guide red light several centimeters into the soil [5]. In addition, Agrobacterium fabrum cells were also found on plant stems and leaves, i.e. in open sunlight environment [6]. For these reasons, it can be assumed that A. fabrum senses light, which is supported by the discovery of two phytochrome photoreceptors Agp1 and Agp2 in the sequencing of A. fabrum C58 genome [7, 8].

Phytochromes sense light in the blue, red and far-red range of the visible spectrum [9]. A large number of developmental effects are controlled by phytochromes in land plants 
[10] and fungi [11], and several examples for phytochrome effects in bacteria have been reported $[12,13]$. In a search for phytochrome responses of $A$. fabrum, knockout mutants were generated which had, however, no apparent phenotype [14]. A first clear Agrobacterium phytochrome response was found by a computer based co-distribution study [15, 16]. In this investigation, we searched for Agp1 and Agp2 BLAST homologs in 43 related species that belong to the Rhizobiales. Then we tested for every other A. fabrum protein whether its BLAST homologs are similarly distributed among this set of species. Agp1 and Agp2 homologs were found in an almost identical subset of species as homologs of TraA, a central player in bacterial conjugation. Experimental tests showed that conjugation of A. fabrum is indeed regulated by light and phytochrome [15]. When strains with Ti plasmid were used, conjugation was drastically reduced by red or far-red light and in $a g p 1^{-}$or agp $2^{-}$knockout mutants. In the $a g 1^{-} / a_{g p 2^{-}}$double knockout, no conjugation was observed. Studies with complementation strains were more complex than expected but showed that the observed mutant effects were clearly the result of the loss of phytochrome.

We found here that phytochromes in A. fabrum have a major impact on plant infection. This response was also light regulated. Mutant results suggested an action of phytochrome in darkness, as in the control of conjugation. We also analyzed effects on A. fabrum growth and motility. In those cases, phytochromes could have an impact independent from light. Finally, the proteomes of dark and light grown wild type and double knockout mutants were compared. These data show that levels of few gene products are affected and suggest regulatory mechanisms independent from transcription or translation. On the level of single proteins, we found phytochrome effects that are light dependent and others that are light independent.

\section{Materials and Methods}

\section{Agrobacterium Strains, Growth Conditions and Motility Assay}

As wild type strain we used Agrobacterium fabrum C58 (former Agrobacterium tumefaciens C58). The name A. fabrum is used here because in protein and genome databases "fabrum C58" is used instead of "tumefaciens C58", according to [17]. The authors are aware that this species name has never been validated (https://lpsn.dsmz.de/speci es/agrobacterium-fabrum). The phytochrome knockout mutants $a g p 1^{-}, a g p 2^{-}$and the double knockout mutant agp 1/2- were generated by homologous recombination as described earlier [14]. These are the same strains that were used for conjugation and other experiments [18]. Agrobacterium fabrum was either grown in LB liquid medium or on $1 \%$ agar plates. For $\beta$-Glucuronidase (GUS) assays, strains with additional pGUSINT vector were used [15, 19]. For growth assays, $100 \mathrm{ml} \mathrm{LB}$ medium was first inoculated to achieve a cell density of $O D_{600 \mathrm{~nm}}=0.05$ and kept at the desired temperature under shaking $(110 \mathrm{rpm})$. The $O D_{600 \mathrm{~nm}}$ was measured every day. Motility assays were performed on $10 \mathrm{~cm} \mathrm{LB}$ agar plates with a reduced agar concentration of $0.5 \%$. This concentration is between the 0.2 or $0.3 \%$ used to analyze flagella driven swimming [20] and the $1 \%$ used to observe type IV pili driven twitching motility [21]. The $\mathrm{pH}$ of the medium was adjusted by adding $\mathrm{HCl}$ or $\mathrm{NaOH}$ before the addition of agar and autoclaving. Eighteen dots of A. fabrum cells were spotted on each plate using a $100 \mu$ pipette tip. Spot sizes were about $0.5 \mathrm{~mm}$. The plates were brought into dark or light and incubated at the temperature given. After $30 \mathrm{~h}$ incubation the diameter of each colony was measured, the diameter was taken as value for motility. The mean value of the 18 diameters was calculated. Each treatment was repeated 3 times and the mean of the three mean values \pm SE calculated.

\section{Arabidopsis Root Infection Assay}

This assay was adopted from [22]. Seeds of Arabidopsis thaliana (ecotype Wassilewskija) were surface sterilized, suspended in $1 \mathrm{ml} 0.1 \%$ agar solution, incubated over night at $4{ }^{\circ} \mathrm{C}$, brought on agar-plates (B5-Gamborgs-Medium, Duchefa, Haarlem, Netherlands, $20 \mathrm{~g} / 1$ sucrose, $7.5 \mathrm{~g} / 1$ Bacto-Agar and $100 \mathrm{mg} / \mathrm{l}$ Cefotaxim) and kept at $20{ }^{\circ} \mathrm{C}$ under $16 \mathrm{~h} \mathrm{light} / 8 \mathrm{~h}$ dark cycles in an incubator (Percival Scientific, Inc., Perry, USA). After $20 \mathrm{~d}$, roots were cut in 3-5 mm segments. 20 bundles of 5 roots were placed on each agar plate $(4.3 \mathrm{~g} / \mathrm{l}$ minimal salts, Duchefa, Haarlem, Netherlands, 0.05 M MES, $0.5 \mathrm{mg} / \mathrm{l}$ nicotinic acid, $0.5 \mathrm{mg} / \mathrm{l}$ pyridoxine, $0.5 \mathrm{mg} / \mathrm{l}$ thiamin, $100 \mathrm{mg} / \mathrm{l}$ myo-inositol, $10 \mathrm{~g} / \mathrm{l}$ sucrose, $7.5 \mathrm{~g} / \mathrm{l}$ Bacto-Agar, pH 5.7). Agrobacterium fabrum wild type and knockout mutants were kept for 3 days at $28{ }^{\circ} \mathrm{C}$ on YEP agar plates. $5 \mathrm{ml}$ YEP liquid medium was inoculated with a single colony and incubated over night at $28{ }^{\circ} \mathrm{C}$. A $50 \mathrm{ml}$ culture was inoculated to a start $O D_{600 \mathrm{~nm}}$ of 0.1 and cultivated under shaking until the $O D_{600 \mathrm{~nm}}=0.8$. Cells were diluted $10 \times$ and transferred by centrifugation into $0.9 \% \mathrm{NaCl}$. Of each suspension, $15 \mu \mathrm{l}$ were pipetted onto a root bundle. During $48 \mathrm{~h}$ the agar plates were kept at $26{ }^{\circ} \mathrm{C}$ in red $\left(40 \mu \mathrm{mol} \mathrm{m} \mathrm{m}^{-2} \mathrm{~s}^{-1}, 655 \mathrm{~nm}\right)$ or darkness. After cocultivation, roots were brought on MS agar medium with $100 \mathrm{mg} / \mathrm{l}$ Cefatoxamin (to inactivate $A$. fabrum). These plates were kept for 2 weeks at $23{ }^{\circ} \mathrm{C}$ in darkness. The number of tumors was counted. Experiments were repeated 3 times independent of each other. 


\section{Infection of Nicotiana benthamiana with Agrobacterium fabrum}

Nicotiana benthamiana was grown for 6 weeks in the greenhouse. For stem assays, the surface of the stem was first cut at 1 to 3 positions with a sterile scalpel. Each cut was $1 \mathrm{~cm}$ long. Agrobacterium fabrum from agar plates was then applied directly onto the wounded sites using a pipette tip. For dark controls, sections were covered with aluminum foil, the other parts were left open. The entire plants were then kept in red light $\left(1 \mu \mathrm{mol} \mathrm{m} \mathrm{m}^{-2} \mathrm{~s}^{-1}, 655 \mathrm{~nm}\right)$ at $25^{\circ} \mathrm{C}$. After $24 \mathrm{~h}$, aluminum foil was removed and the bacterial growth was terminated by pipetting $500 \mu \mathrm{l}$ of $220 \mu \mathrm{M}$ cefotaxime into each cut. Thereafter, the plants were kept at room temperature under daylight. After 6 weeks, tumors of the wound were observed and photographs were taken. For leaf assays, bacteria with the pGUSINT vector [19] were propagated in liquid LB medium at $28{ }^{\circ} \mathrm{C}$ until $O D_{600 \mathrm{~nm}}$ reached 2 . The GUS assay is described also in [1]. After centrifugation at $5000 \mathrm{~g}$ for $15 \mathrm{~min}$, the supernatant was removed and the pellet was suspended in $11 \mathrm{mM}$ MES, $10 \mathrm{mM} \mathrm{MgCl}$, $\mathrm{pH} 7$ to the final $O D_{600 \mathrm{~nm}}$ of 0.8 . Two $\mathrm{ml}$ of this solution were infiltrated into a plant leaf from 6 week old plants as above by using a syringe without cannula. Thereafter, the plants were kept for $24 \mathrm{~h}$ in red light $\left(1 \mu \mathrm{mol} \mathrm{m} \mathrm{m}^{-2} \mathrm{~s}^{-1}\right)$ or in darkness. For GUS staining [23], the leaves were cut off and placed into X-Gluc staining solution containing $2 \mathrm{mM}$ 5-bromo4-chloro-3-indolyl glucuronide (X-Gluc, Thermo Fisher), $200 \mathrm{mM}$ sodium phosphate ( $\mathrm{pH} 7)$, and $0.01 \%$ (v/v) Triton $\mathrm{X}-100$ at $37{ }^{\circ} \mathrm{C}$ for $17 \mathrm{~h}$ in darkness. After soaking the leaves in ethanol (first $70 \%$, then $80 \%$, then $90 \%$, then $100 \%$ ), the blue GUS stains were observed and photographed. For GUS fluororimetric assays, leaf extracts were incubated in reaction mix containing $50 \mathrm{mM}$ sodium phosphate, $10 \mathrm{mM}$ EDTA, $0.1 \%$ (w/v) SDS, $0.1 \%$ (v/v) Triton X-100, $1 \mathrm{mM}$ 4-MUG (4-Methylumbelliferyl- $\beta$-D-glucuronide hydrate, Sigma), pH 7 for $17 \mathrm{~h}$ at $37{ }^{\circ} \mathrm{C}$ in darkness [23, 24]. The reaction was stopped by the addition of $1 \mathrm{M} \mathrm{Na}_{2} \mathrm{CO}_{3}$ to a final concentration of $0.99 \mathrm{M}$. The fluorescence was measured with a Jasco FP 8300 fluorimeter; excitation and emission wavelengths were $365 \mathrm{~nm}$ and $455 \mathrm{~nm}$, respectively. Normalization of the GUS activity calculated as nmol of 4-MU per minute per leaf was performed using 4-MU with concentrations of $0.5,5,50$, and $500 \mathrm{nM}$.

\section{Proteome Studies}

Colonies of $A$. fabrum wild type or agp $1 / 2^{-}$double knockout mutant were used to inoculate $100 \mathrm{ml} \mathrm{LB}$ and the cultures were shaken overnight $\left(28{ }^{\circ} \mathrm{C}, 110 \mathrm{rpm}\right)$. The suspensions were diluted to an $O D_{600 \mathrm{~nm}}$ of 0.6 and a volume of $100 \mathrm{ml}$. Half of the culture flasks were wrapped in aluminum foil ("darkness"). All culture flasks where shaken for $24 \mathrm{~h}$ under white light $\left(40 \mu \mathrm{mol} \mathrm{m} \mathrm{m}^{-2} \mathrm{~s}^{-1}\right)$. Two $\mathrm{ml}$ cultures were centrifuged at $12,000 \times g$ for $5 \mathrm{~min}$ at $4{ }^{\circ} \mathrm{C}$. The cell pellets were washed three times with cold $10 \mathrm{mM}$ Tris/Cl, $1.4 \mathrm{mM}$ PMSF, 1 mM EDTA, pH 7.5 and frozen to $-80^{\circ} \mathrm{C}$. Subsequent steps were performed by the company Mtoz Biolabs (Mtoz Biolabs Inc, Boston, MA USA). About $80 \mathrm{mg}$ frozen cells were suspended in $0.3 \mathrm{ml}$ lysis buffer $(50 \mathrm{mM}$ Tris, $5 \%$ SDS, $0.1 \mathrm{mM}$ EDTA, $150 \mathrm{mM} \mathrm{NaCl}, 1 \mathrm{mM} \mathrm{MgCl}_{2}, 50 \mathrm{mM}$ dithiothreitol, pH 8) [25] and homogenized. The supernatant was collected after centrifugation at $10,000 \times g$ for $5 \mathrm{~min}$ at $4{ }^{\circ} \mathrm{C}$. The protein concentration was measured with Pierce ${ }^{\mathrm{TM}}$ BCA Protein Assay Kit (Thermo Fisher Scientific). Supernatant samples were diluted with $50 \mathrm{mM}$ triethylammonium bicarbonate (TEAB) $(\mathrm{pH} 8.5)$ to a final protein concentration of $1 \mu \mathrm{g} / \mu \mathrm{l}(100 \mu \mathrm{l})$, reduced by $10 \mathrm{mM}$ tris (2-carboxyethyl) phosphine $(\mathrm{pH} 7)$ at $56^{\circ} \mathrm{C}$ for $1 \mathrm{~h}$ and alkylated by $20 \mathrm{mM}$ iodoacetamide in darkness for $1 \mathrm{~h}$ at room temperature. After the addition of $600 \mu \mathrm{l}$ cold acetone and incubation at $-20{ }^{\circ} \mathrm{C}$, the mixture was centrifuged at $8000 \mathrm{~g}$ for $10 \mathrm{~min}$ at $4{ }^{\circ} \mathrm{C}$. The acetone supernatant was removed and the pellet was dried for 2-3 min, reconstituted with $100 \mu 150 \mathrm{mM}$ TEAB ( $\mathrm{pH} 8.5$ ) and finally digested overnight at $37^{\circ} \mathrm{C}$ by adding $2.5 \mu \mathrm{g}$ trypsin (Madison, WI, USA). Peptides were labeled with tandem mass tags (TMT, Thermo Fisher Scientific Inc.) as listed in Table S1. Six samples from each group were mixed together for nanoscale liquid chromatography and tandem mass spectrometry (nano LC-MS/MS) analysis.

The nanoflow ultra high-performance liquid chromatography (UPLC) LC-MS/MS analysis was performed by a Dionex Ultimate 3000 Nano liquid chromatography (LC) system with Orbitrap Q Exactive ${ }^{\mathrm{TM}}$ mass spectrometer (MS/ MS Thermo Fisher Scientific, USA) with an electrospray ionization nanospray source. LC was performed with an Easy-nLC1000 system (ThermoFisher Scientific, USA) equipped with a $100 \mu \mathrm{m} \times 10 \mathrm{~cm}$ in-house made nanocolumn, packed with a reversed-phase ReproSil-Pur C18-AQ resin ( $3 \mu \mathrm{m}, 120 \AA$, Dr. Maisch GmbH, Germany). Of each sample, $5 \mu \mathrm{l}$ were loaded into the nanocolumn. The mobile phase was $0.1 \%$ formic acid in water (A) and $0.1 \%$ formic acid in acetonitrile (B). The peptides were separated at a flow rate of $600 \mathrm{nl} / \mathrm{min}$ with LC linear gradient: $15 \mathrm{~min}$, from 6 to $9 \% \mathrm{~B} ; 20 \mathrm{~min}$, from 9 to $14 \% \mathrm{~B} ; 60 \mathrm{~min}$, from 14 to $30 \% \mathrm{~B} ; 15 \mathrm{~min}$, from 30 to $40 \% \mathrm{~B} ; 3 \mathrm{~min}$, from 40 to $95 \% \mathrm{~B} ; 7 \mathrm{~min}, 95 \% \mathrm{~B}$. The $\mathrm{MS}$ parameters, resolution and precursor $\mathrm{m} / \mathrm{z}$ range were set to 60,000 and $300-1650$, respectively. The 15 most intense peptide ions from the MS scan were fragmented by collision-induced dissociation (40\% normalized collision energy). We used the Orbitrap with a resolution of 15,000 for MS/MS scan. The raw MS dates were analyzed and searched with Proteome Discover 2.1 software (Thermo Fisher Scientific) against the protein database of $A$. fabrum. The entire procedure was repeated 
with 3 independent samples of each condition (wild type / mutant, light / dark).

\section{Results}

\section{Growth in Liquid Medium}

In earlier studies we found no effect of phytochromes on A. fabrum growth in liquid culture, but in these studies growth was followed for $6 \mathrm{~h}$ only [14]. In the present study, we expanded the growth period and performed assays at different temperatures, because Agp1 might also function as a thermosensor $[15,26]$. The growth at $28{ }^{\circ} \mathrm{C}$ was not significantly different between wild type and mutants up to $6 \mathrm{~h}$, as in the earlier studies, but thereafter, all three mutants displayed faster growth than the wild type (Fig. 1a, b). The agp1- knockout strain had the fastest growth and reached $2 \times$ higher cell densities than the wild type at $51 \mathrm{~h}$. These results show that Agp1 and Agp2 act inhibitory on growth in the later growth stage,
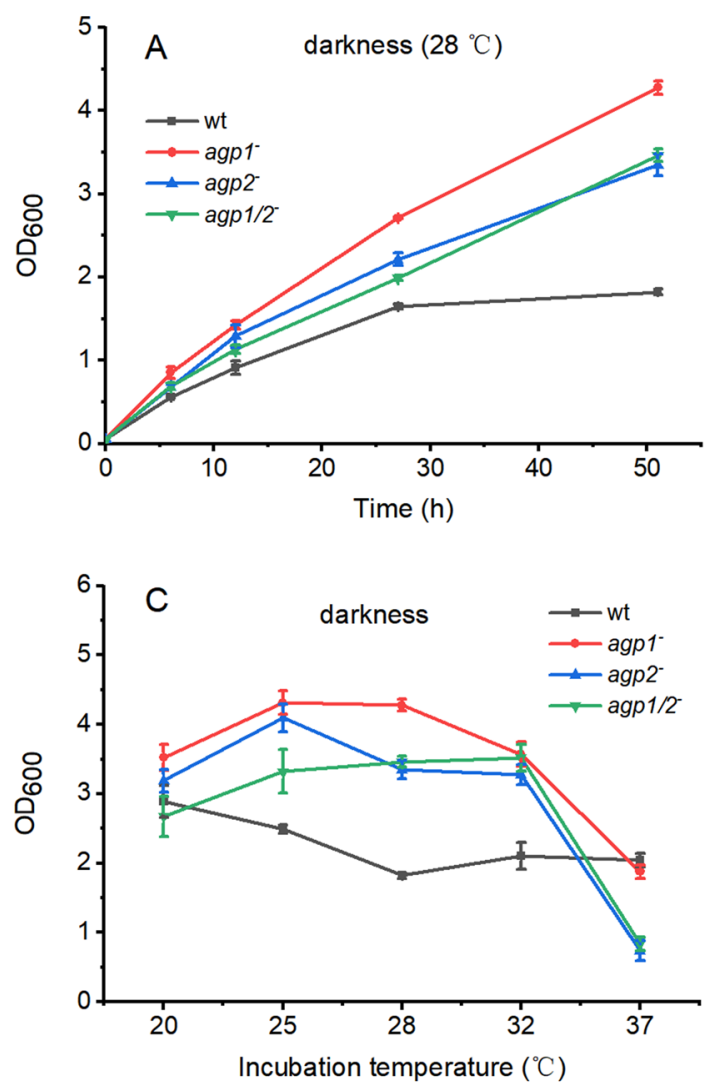

Fig. 1 Effects of phytochromes Agp1 and Agp2 on growth of A. fabrum in liquid culture. a and cell densities $\left(\mathrm{OD}_{600}\right)$ plotted over time for wild type (wt) and phytochrome mutants of A. fabrum during growth in darkness at $28{ }^{\circ} \mathrm{C}$ (a) and $37{ }^{\circ} \mathrm{C}(\mathbf{c})$. Effect of white, red i.e. under nutrient deprivation. That all three phytochrome mutants grow faster than the wild type makes it unlikely that the effects result from a second-site mutation. Agp2 seems to dominate the effect in the wild type, since the response of the double knockout mutant is comparable

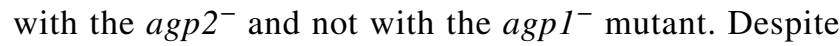
the clear mutant effects, we observed no impact of light on the growth at $28^{\circ} \mathrm{C}$ (Fig. 1 b). At $37^{\circ} \mathrm{C}$, the cell densi-

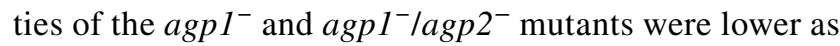
compared to the wild type and there was a clear inhibitory effect of red light on wild type and the agp1- mutant. Therefore, red light regulation at $37{ }^{\circ} \mathrm{C}$ is mediated through Agp2. White light and blue light acted similarly. Both induced a slight increase in cell densities in wild type and agpl $^{-}$knockout and a strong increase in the agp $2^{-}$knockout. An induction of growth was induced by blue light in the double knockout (Fig. 1). Agrobacterium fabrum has no LOV or BLUF protein homolog, which could serve as alternative photoreceptors. The photolyase $\mathrm{PhrB}$, which has been identified by a blue light effect on
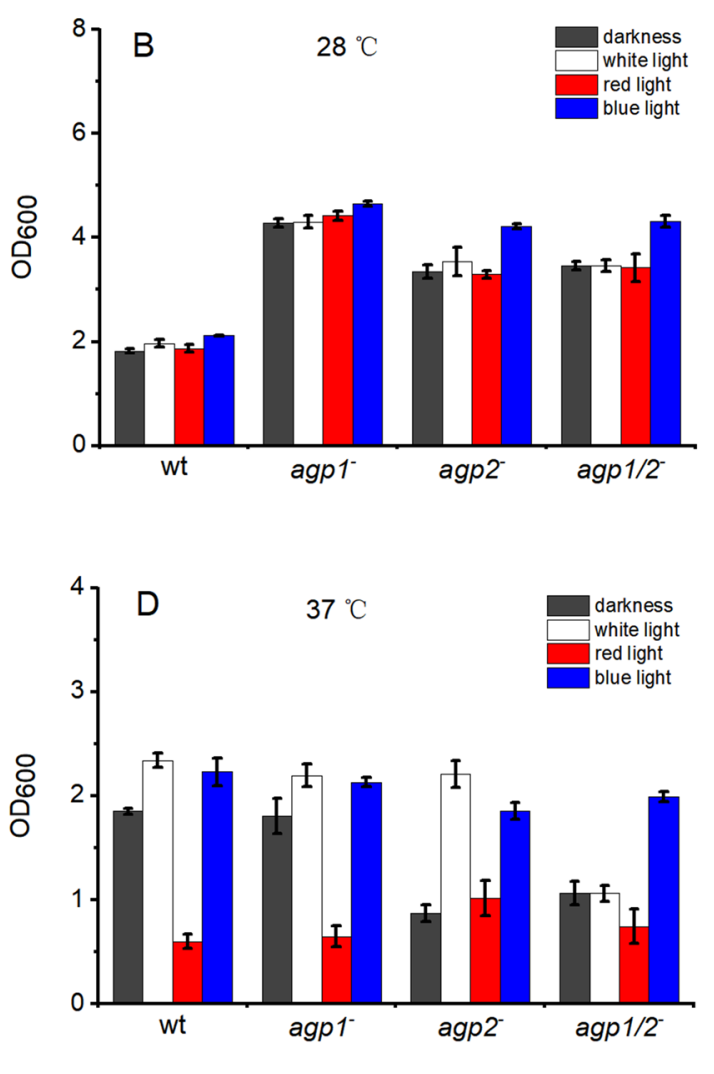

$(655 \mathrm{~nm})$, blue light $(470 \mathrm{~nm})$ and darkness on cell densities $\left(\mathrm{OD}_{600}\right)$ of wild type and mutants of A. fabrum, $51 \mathrm{~h}$ after inoculation; cultivation at $28{ }^{\circ} \mathrm{C}(\mathbf{b})$ and $37{ }^{\circ} \mathrm{C}(\mathbf{d})$. Light intensities were always $40 \mu \mathrm{mol} \mathrm{m} \mathrm{m}^{-2} \mathrm{~s}^{-1}$. Mean values of three independent experiments $\pm \mathrm{SE}$ 
motility $[27,28]$ is probably the photoreceptor of these light responses in the absence of phytochromes.

\section{Cell Motility}

An assay for cell motility or swimming of A. fabrum is based on the increase in colony diameter during a certain period of time. In earlier swimming plate studies, light reduced the motility of $A$. fabrum significantly; this effect led to the discovery of the (6-4) photolyase PhrB [29]. We performed here similar studies with the focus on phytochrome effects. When these motility experiments were performed on standard medium under different light conditions and with different knockout mutants, we found no clear light effect and no clear effect of the knockout mutations, in contrast to earlier studies [29]. We therefore expanded our conditions to a broad range of $\mathrm{pH}$ and to two different temperatures -26 and $37^{\circ} \mathrm{C}$. Since spectral properties of Agp2 are $\mathrm{pH}$-dependent [30] and Agp1 could act as thermosensor [26], it seemed reasonable to us that a possible impact of phytochrome and light on swimming could be uncovered by $\mathrm{pH}$ and temperature variations. An example of the variation in colony diameters at different $\mathrm{pH}$ is shown in Fig. S1. The whole set of data obtained at different $\mathrm{pH}$, light, and temperatures is shown in Fig. S2. In most treatments, colony diameters of A. fabrum were smaller at $\mathrm{pH} 5$ or $\mathrm{pH} 9-11$ as compared to the neutral range of $\mathrm{pH} 6-8$. In the neutral range, the single knockout mutants had slightly larger diameters than the wild

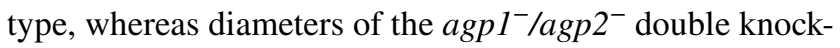
out were slightly smaller (Fig S2A). This points to a weak light independent effect of Agp1 and Agp2 on cell motility.

The dark-minus-light differences and the error bars of these differences together with t-test significances are shown in Fig. 2. Almost all colony diameters in white, red or far-red light were smaller than those in the dark, leading to positive difference values (Fig. 2a-c). The highest difference values, i.e. the strongest light effects were observed at $\mathrm{pH} 5$. The white light effects were weaker than those of the earlier study [29]. White, red and far-red light resulted in a larger effect in the single knockout mutants as compared to wild type and double knockout (Fig. 2g, h). This suggests that each phytochrome acts also inhibitory on the light effect on motility, because changes are larger in absence of Agp1 or Agp2. In the double knockout, no light effects or stimulatory light effects (with negative difference values) were seen. This suggests that in the wild type, both phytochromes together act as photoreceptors for this light response. The "stimulatory light effect" was especially found for the far-red treated double knockout sample at $\mathrm{pH} 5$ and $\mathrm{pH} 6$. These are probably no outliers, as also other samples had a negative difference value (Fig. 2). Clearly, phytochromes cannot be photoreceptors for the stimulatory light response of the double knockout mutant (or for any light response). We are also not aware of another photoreceptor that could sense long wavelength red light in A. fabrum. We can only imagine that the negative response resulted from local warming induced by the light. The effect of local warming should as well take place in wild-type and single mutants. Since the inhibitory red/far-red light effects are antagonistic to the stimulatory effect, the proposed inhibitory role of both phytochromes in the wild type (Fig. 2a-c) is still valid.

The $37{ }^{\circ} \mathrm{C}$ experiments were performed in dark and white light only. In many conditions, the colony diameters were zero, i.e. the cultures died. Altogether, less data are available as for the $26^{\circ} \mathrm{C}$ experiments. White light induced cell death at $\mathrm{pH} 9$ in wild-type cells and at $\mathrm{pH} 9, \mathrm{pH} 8$ and $\mathrm{pH}$
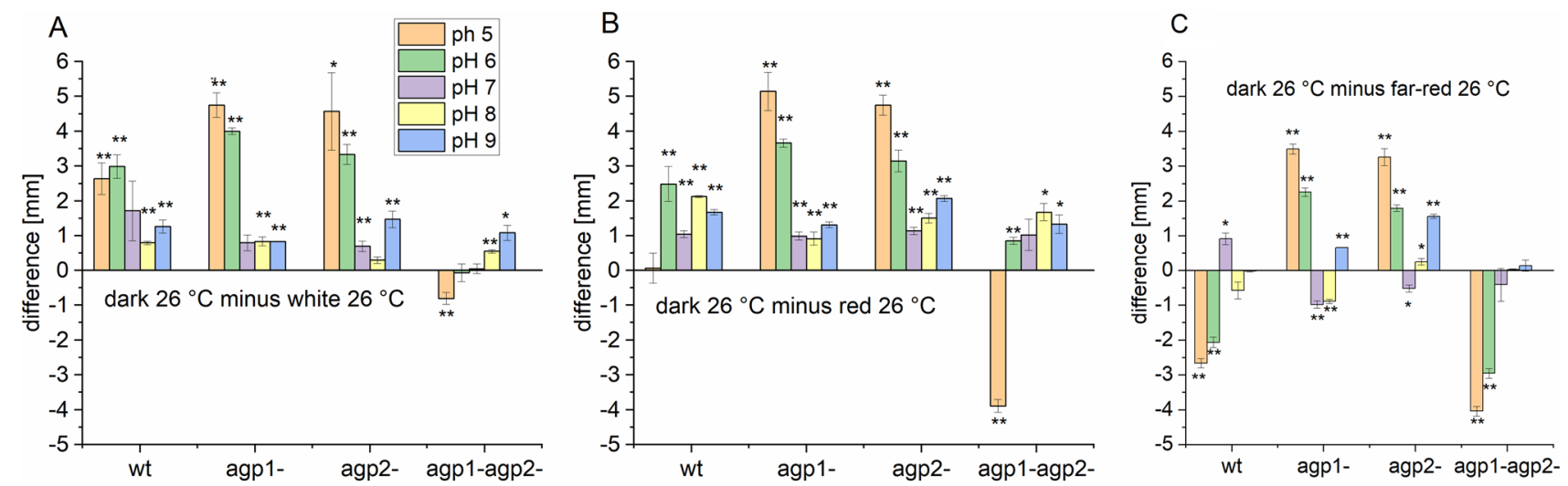

Fig. 2 Light and mutant effects on cell motility of A. fabrum at different $\mathrm{pH}$. Mean values \pm standard errors (SE) of differences of colony diameters. a differences between darkness and white light, $\mathbf{b}$ differences between darkness and $655 \mathrm{~nm}$ red light, $\mathbf{c}$ differences between darkness and $780 \mathrm{~nm}$ far-red light. Colony diameters were determined $30 \mathrm{~h}$ after inoculation at $26{ }^{\circ} \mathrm{C}$, light intensities were always
$40 \mu \mathrm{mol} \mathrm{m} \mathrm{m}^{-2} \mathrm{~s}^{-1}$. The subtractions are based on the data presented in Fig. S2. Errors were calculated according to the laws of propagation of uncertainty. $T$ test results for significant differences between dark and light treated samples are indicated by $*(<5 \%$ error probability $)$ or $* *(<1 \%$ error probability $)$ 
5 in single knockout mutants (Fig. S2F and G); the colony diameters were zero under these conditions. In the double knockout, no cell death was induced by white light. This result shows that the effect of light on cell death is mediated through phytochrome(s) in wild type and single knockouts.

\section{Plant Infection}

We analyzed A. fabrum light and phytochrome effects on virulence by root infection, stem infection and leaf infection assays. The root infection is monitored by tumor formation on root segments of Arabidopsis thaliana two weeks after cocultivation under different light (see Fig. S3 for tumor formation). We could perform only a limited number of experiments: the Arabidopsis roots must have appropriate size and age, and the plants must grow at constant temperature, since otherwise the variations are too large. We could obtain these conditions for experiments with A. fabrum wild type and the double knockout mutant in darkness and red light. The infection of Arabidopsis thaliana roots was clearly

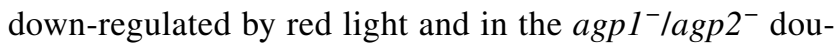
ble knockout mutant (Fig. 3). There was no light effect in experiments with the A. fabrum double knockout mutant. We therefore assume that induction of tumors is completely regulated through the A. fabrum phytochromes and that the plant light perception system does not play a role. The same argument holds for experiments on stem and leaf infection described below.

Stem infection assays were performed with Nicotiana benthamiana plants (Fig. 4a). In this case, we assayed also tumor formation. A. fabrum cells were transferred

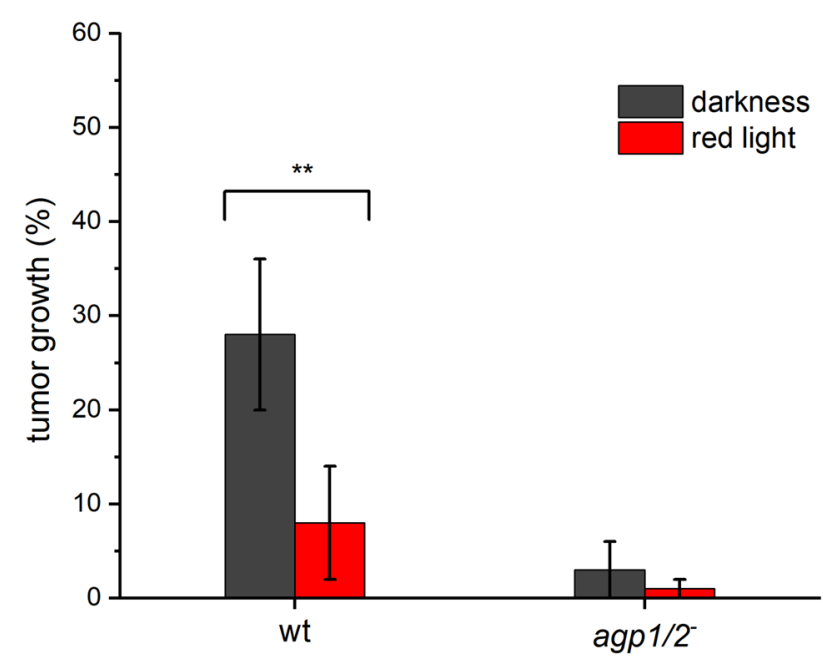

Fig. 3 Arabidopsis thaliana root infection by A. fabrum wild type and agp $1 / 2^{-}$mutant under dark and red light $\left(40 \mu \mathrm{mol} \mathrm{m} \mathrm{m}^{-2} \mathrm{~s}^{-1}\right)$. A. fabrum suspensions were pipetted on root segment bundles and incubated for 2 days. The number of tumors was counted after 2 weeks. An example photo is shown in Fig. S1. Mean of 3 experiments \pm SE to 2 injured sections on the same plant above each other. For a dark control, one section was covered with aluminum foil. Plants were kept for 1 day in red light, thereafter the aluminum foil was removed and bacterial cells were destroyed. After two weeks the formation of tumors could be observed in the dark controls of wild type or agp1- infected stems, but not in the parts of the stems that were exposed to red light during infection. The results were reversed for the $a g p 2^{-}$mutant, in this case larger tumors were formed in the light and weak tumors in dark-

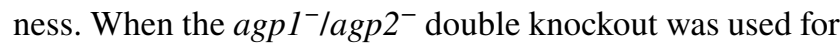
stem infection, there were no tumors or only small tumors formed both in light and darkness. After plant growth of 6 weeks, tumors were increased but the differences between the different treatments remained (Fig. 4a). Note that here and in the root infection experiments (Fig. 3) the major difference between A. fabrum wild type and phytochrome double knockout is observed in darkness, i.e. indicates a dark action of phytochromes.

Nicotiana benthamiana leaf infection assays were monitored by glucuronidase (GUS) expression. For these assays, A. fabrum wild-type and phytochrome mutants with the pGUSINT vector $[15,19]$ that induces expression of GUS in infected cells (Fig. 4b, c), were used. X-Gluc results in a blue staining of these cells (Fig. 4b). With wild type A. fabrum, cells were infected after dark incubation but not after incubation in red light. When leaves were infiltrated with agp1 $1^{-} / a g p 2^{-}$double knockout mutant cells, no staining was observed. Infiltration with agp ${ }^{-}$knockout mutants resulted in staining in the red irradiated leaf, but not in the dark control. With the agp $2^{-}$knockout mutant, the result was again reversed: cells were stained after dark incubation but not after red light treatment.

For better quantification, this assay was also performed with methylumbelliferyl- $\beta$-D-glucuronide (MUG) [24]. These measurements confirmed the X-Gluc results. After treating the leaves as above, leaf extracts were mixed with MUG and the fluorescence of the GUS product methylumbelliferol (MU) was measured. The MU signal was again strong in the dark control, whereas red light resulted in

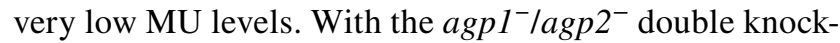
out the MU signal was always low. The light/dark pattern of the agp $1^{-}$mutant was again similar as the wild type and the pattern of the agp $2^{-}$knockout mutant again reversed.

All infection assays show that the gene transfer from A. fabrum to plant is controlled by light and by both phytochromes. In both kinds of DNA transfer -conjugation and plant infection-the transfer is efficient in darkness and suppressed in the light. Simply speaking, phytochromes are active in darkness and inactive in the light. The presence of Agp1 and Agp2 is required for most efficient gene transfer. A plant phytochrome or other plant photoreceptors could also mediate light effects on plant 
Fig. 4 a Infection of Nicotiana benthamiana stems by A. fabrum wild type (WT) and phytochrome mutants as indicated above the panels. During $1 \mathrm{~d}$ infection, the upper part of the stem was covered with aluminum and the entire plant placed in red light $\left(1 \mu \mathrm{mol} \mathrm{m} \mathrm{m}^{-2} \mathrm{~s}^{-1}\right)$. Stems with or without tumors were photographed after 6 weeks.

The experiments were repeated 3 times with similar outcome. b Nicotiana benthamiana leaves were infected with $A$. fabrum WT and phytochrome mutants (agp1 $1^{-}$, agp $2^{-}$and $\left.a g p 1 / 2^{-}\right)$and the GUS activity stained with X-Gluc. c Quantification of leaf infection assay by MUG assay. Mean values of 3 independent infected leaves $\pm \mathrm{SE}$
A

wt
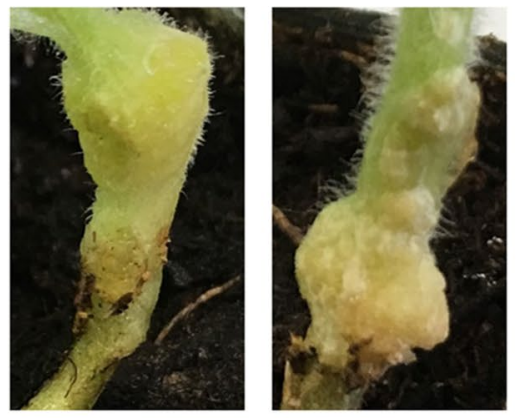

Darkness

Red light
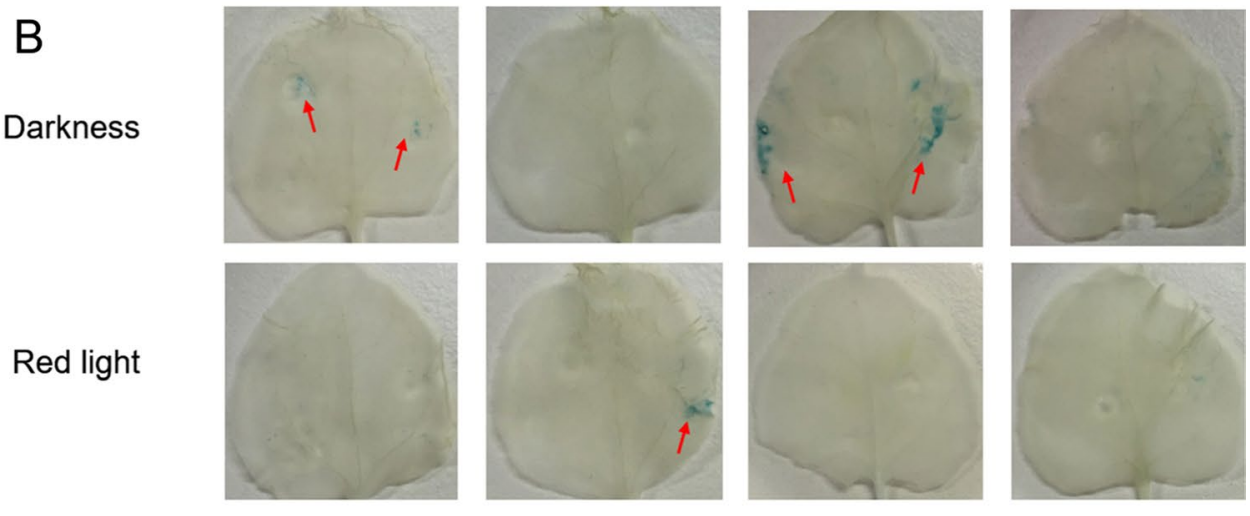

C

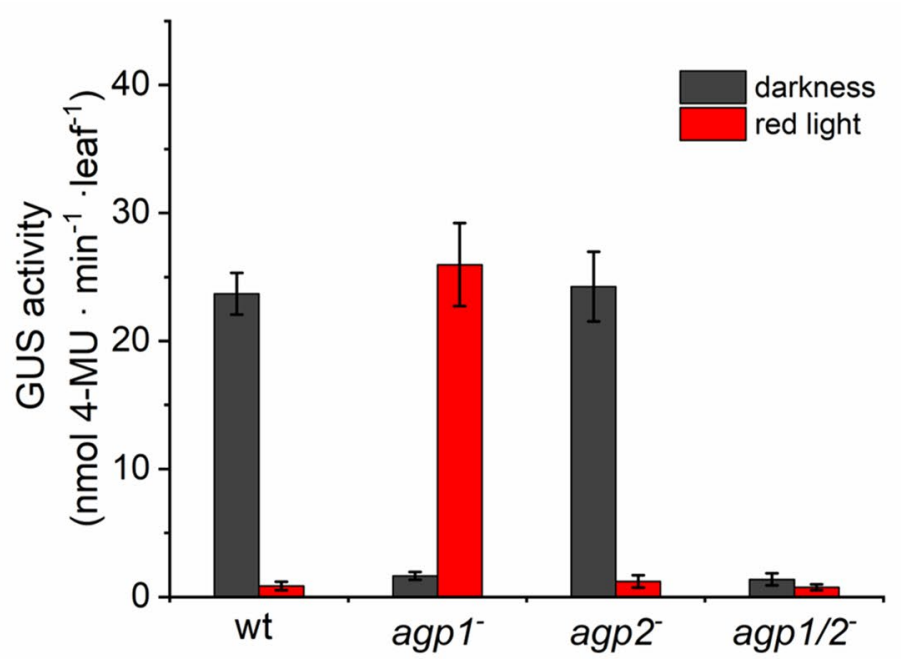

infection, but the light effects seen here are clearly mediated by Agp1 and Agp2.

\section{Proteome Studies}

In order to find light versus dark or mutant versus wild type differences on the level of proteins, we performed a comparative TMT proteome analysis [31]. In this approach, proteins from cell extracts are digested by Trypsin and covalently labeled with tags of slightly different weight to mark each specific sample (Table S1). After labeling, samples are mixed and subjected to LC-MS/MS. The quantity of each peptide relative to the same peptide of another sample can be gained from comparison in the same run. The analysis was performed with 3 independent extracts of 4 different samples, wild type, double knockout both in dark and light. Out of 5400 A. fabrum proteins, 2814 were identified. We considered protein ratios of $<0.67$ or $>1.5$ with $t$ test probabilities $<0.05$ as significant. An overview of the differences is given in the Venn diagram in Fig. 5. Of the 2814 detected proteins, 422 proteins were either light regulated or affected by the knockout mutation. In the wild type, 24 proteins 


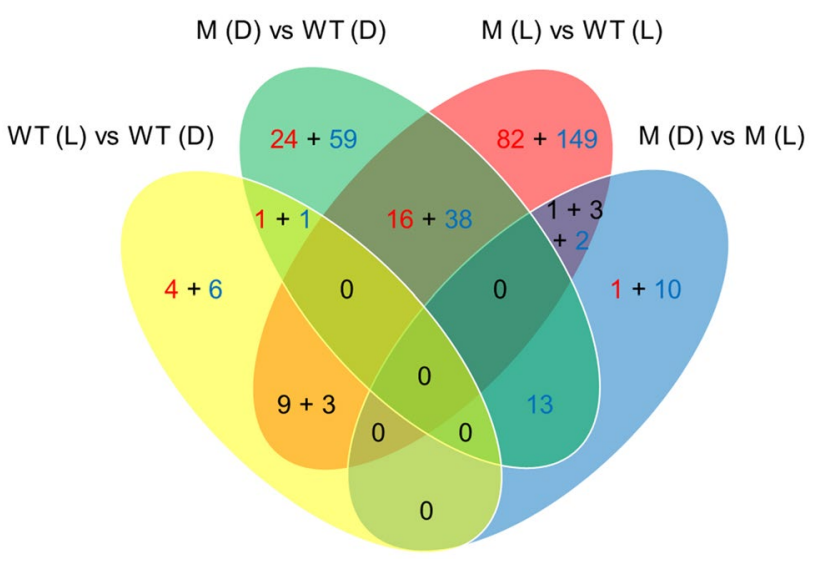

Fig. 5 Differentially expressed proteins as identified by TMT analysis, Venn diagram. WT (D): wild type (darkness); WT (L): wild type (white light); M (D): mutant agp1/2- (darkness); M (L): mutant agp 1/2- (white light). Ratio (experimental group versus control group $)>1.5(P<0.05)$ and $<0.67(P<0.05)$ were set as significantly up-regulated (red numbers) and down-regulated (blue numbers), respectively. The black numbers $9+3$ indicate that 9 proteins were down-regulated in WT (L) versus WT (D), and up-regulated in M (L) versus WT (L) and 3 proteins were up-regulated in WT (L) versus WT (D) and down-regulated in M (L) versus WT (L). The black numbers $1+3$ indicate that 1 protein was up-regulated in $M(L)$ versus WT (L) and down-regulated in M (D) versus M (L) and 3 proteins were down-regulated in WT (L) versus WT (L) and up-regulated in $M(D)$ versus $M(L)$. The sum of differentially expressed proteins and identified protein was 422 and 2812, respectively. 134 and 353 proteins were only observed in both WT (D) and M (D) and both WT (L) and $\mathrm{M}(\mathrm{L})$, respectively

appeared light regulated (Table S2 and S3). Ten of the 24 proteins showed light / dark differences in the wild type only, but not in the double mutant (Table S2). Seven light regulated proteins have functions in energy metabolism, three are ribosomal proteins, two are signal transduction proteins, one is a diguanylate phosphodiesterase and one a Ras family protein. On this level, no overlap with the physiological functions above is apparent. Quite interestingly, 24 proteins were light regulated in the double knockout mutant and not in the wild type. These effects could also be mediated by the photolyase $\mathrm{PhrB}$, as discussed above for physiological responses.

More differences were found between the mutant and wild-type strains. Altogether, 382 proteins had a different abundance in mutant and wild type (Fig. 5). These results suggest that besides their roles as photoreceptors, phytochromes have also other functions both in darkness and in light, in line with the above phytochrome effects on growth.

In the following, we focus on proteins related to motility, conjugation, plant infection and type IV secretion, for which phytochrome effects have been found.

\section{Motility}

Out of 8 detected chemotaxis proteins, one (McpC) showed 0.4 -fold ratio between mutant and wild type, the others were not affected by light or mutant (Table S4). Of the 34 flagella proteins, 11 were detected in the assay (Table S5). For 8 of these, no significant differences between dark versus light or mutant versus wild type were detected. For FlaA and FlaB, the major constituents of the bacterial flagella, the protein levels in the mutant were ca. 1.7 fold higher as compared to the wild type.

The type IV pili might contribute to movement on agar surface. In the present assay, 5 out of 10 type IV pili proteins were detected (Table S6). Two of these, CtpA and CtpE, revealed differences between mutant and wild type. CtpA of light samples was ca. 1.5 fold higher in the mutant, $\mathrm{CtpE}$ levels were 0.5 times lower in the mutant, both in light and dark samples.

\section{Conjugation}

Four of 22 proteins that are related to bacterial conjugation were detected in the assay (Table S7). All four proteins revealed differences between mutant and wild type. The central conjugation protein TraA cleaves the plasmid DNA, forms a covalent link with the DNA and unwinds the double stranded DNA. Agrobacterium fabrum has three TraA proteins that are encoded on the circular chromosome, the AT-plasmid and the Ti-plasmid [15]. Of these, only the AT-plasmid encoded TraA (Atu5111) was detected and the detection was only possible for dark samples. This points to light regulation of this TraA by phytochrome. The levels of the mutant were about 3 times lower as of the wild type.

\section{Virulence}

Of the 26 proteins assigned to plant infection or virulence, only 2 were detected (Table S8), VirH1 and AcvB. Levels of both proteins were unchanged in mutant versus wild type or dark versus light.

\section{Type IV Secretion System}

The type IV secretion system is important for both conjugation and plant infection. Eight of 26 proteins were detected (Table S9). AvhB1 was different between wild type dark and wild type light and three others, AvhB4, AvhB9 and AvhB10, were different between mutant and wild type. 


\section{Type VI Secretion System}

Through type VI secretion system, toxin proteins are injected in competing bacterial cells [32]. We found two proteins with wild-type vs. mutant differences (Table S10) that belong to the type VI secretion system. The levels of the secretion protein Hcp were lower in mutant than in wild-type cells (light and dark). One toxin protein, Atu4347, annotated as peptidoglycan amidase, had lower levels in the mutant (light) as compared to the wild type (light). These proteins are involved in interbacterial competition. Preliminary experiments suggest indeed that phytochromes could play a role in interbacterial competition (data not shown).

\section{Discussion}

We provide evidence for the involvement of bacterial phytochromes in the regulation of plant infection, in motility and growth in liquid culture. The regulation of bacterial conjugation by phytochromes has been reported in an earlier study [15]. The present proteome studies provide us with further information on phytochrome effects in A. fabrum.

The phytochrome mediated regulation of plant infection by light can be regarded as the most important finding of the present work. The mechanism of DNA transfer has been studied intensively and is used by many botanical groups for plant transformation [33]. Our data show that we indeed observe phytochrome responses of A. fabrum and not effecte that are mediated by the plant or other factors [34], because of the major difference between the A. fabrum double knockout mutant and the wild type. That all three plant infection effects under investigation-root-, stem- and leaf-infection-have a similar pattern with respect to light and dark differences and wild type and mutant differences makes us confident that we observed true $A$. fabrum phytochrome effects.

Plant infection and conjugation (in presence of the Ti plasmid) [15] are high in the dark and low or zero in the light. In the wild type, phytochromes could act on these effects either inhibitory in the light or stimulatory in darkness. The double knockout results show that phytochromes must be active in the dark: the loss of both phytochromes results in a loss of the effect in darkness. We would like to stress here that this dark action of phytochrome is a major difference between A. fabrum and the general phytochrome regulation pattern of plants. In principal, plant phytochromes have no dark activity, as concluded from mutant studies: dark grown phytochrome mutant seedlings are usually not different from wild-type seedlings [35]. In a publication by Hangarter et al. [36], evidence for dark activity of phytochrome was provided, but later discussed as second-site effect of the mutant. Earlier, our group has found evidence for dark activity at elevated temperature [37]: Dark grown Arabidopsis phytochrome B mutant seedlings grew shorter than the wild type at $32{ }^{\circ} \mathrm{C}$. To our knowledge, this is however the only report for a dark action of plant phytochromes, we must assume that generally, plant phytochromes are only active after illumination. Fungal phytochromes on the other hand do reveal clear dark activity [38]. A common feature of fungal and bacterial phytochromes like Agp1 and Agp2 is the biliverdin chromophore, whereas plants have a phytochromobilin chromophore. Fungal and bacterial phytochromes are light regulated histidine kinases, whereas plant phytochromes have lost their histidine kinase activity. Indeed, the histidine kinase activity of Agp1 is strong in darkness and down-regulated in the light [37], in agreement with the dark activity of Agp1 in conjugation and plant infection. In addition to the dark activity of phytochromes in A. fabrum, we also distinguished between light-dependent

Table 1 Summary of phytochrome effects in A. fabrum

\begin{tabular}{|c|c|c|c|c|c|c|c|c|c|}
\hline & \multicolumn{2}{|c|}{ Wild type } & \multicolumn{2}{|c|}{ agp1 $1^{-}$knockout } & \multicolumn{2}{|c|}{ agp2- knockout } & \multicolumn{3}{|c|}{ 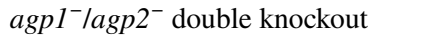 } \\
\hline & Dark & Light & Dark & Light & Dark & Light & Dark & Light & $\begin{array}{l}\text { Dark action of } \\
\text { Agp1 or Agp2 }\end{array}$ \\
\hline \multicolumn{10}{|c|}{ Light dependent phytochrome effects } \\
\hline Motility at $26^{\circ} \mathrm{C}$ & Normal & Normal & Normal & Lower & Normal & Lower & Normal & Normal & \\
\hline Motility at $37^{\circ} \mathrm{C}$ & Normal & Normal & Normal & Dead at extreme $\mathrm{pH}$ & Normal & Dead at extreme $\mathrm{pH}$ & Normal & Normal & \\
\hline Conjugation & Normal & Low & Low & Very low & Low & Very low & Zero & Zero & Yes \\
\hline Root infection & Normal & Low & n.d & n.d & n.d & n.d & Low & Very low & Yes \\
\hline Stem infection & Normal & Low & Low & Normal & Normal & Low & Very low & Very low & Yes \\
\hline Leaf infection & Normal & Very low & Very low & Normal & Normal & Very low & Very low & Very low & Yes \\
\hline \multicolumn{10}{|c|}{ Light independent phytochrome effect } \\
\hline Growth at $28^{\circ} \mathrm{C}$ & Normal & Normal & High & High & High & High & High & High & Yes \\
\hline Growth at $37^{\circ} \mathrm{C}$ & Normal & Normal & Normal & Normal & Low & Normal & Low & Low & Yes \\
\hline
\end{tabular}


effects, such as conjugation and plant infection, and light independent phytochrome effects, such as growth (Table 1). The majority of protein differences on our proteome study belongs to the light independent effects.

The agp $1^{-}$mutant pattern on plant infection is paradox: in this mutant, the light/dark pattern is reversed (Fig. 4), whereas in the agp2- mutant, the light / dark pattern is like that of the wild type. A reversion of light regulation is found both in stem infection and in leaf infection assays. Such a reversion must be based on both inhibitory and inductive action of phytochromes, and could be related to an interaction of both phytochromes. We have shown earlier that Agp1 and Agp2 interact with each other physically and that spectral properties and autophosphorylation are modulated

A

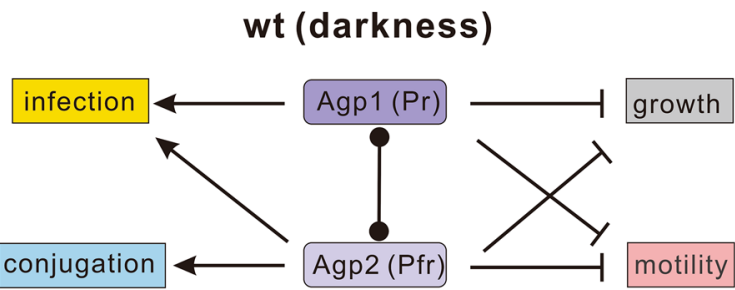

B

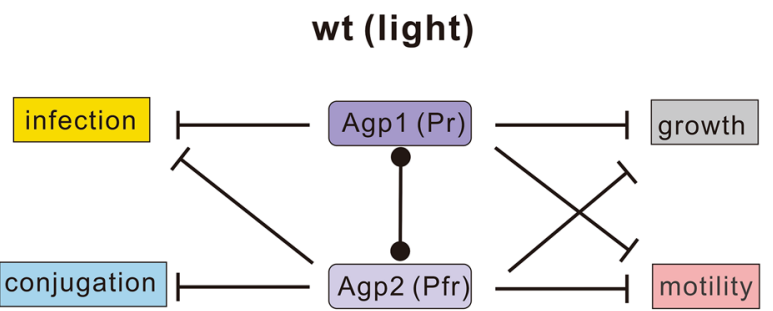

C

$\operatorname{agp} 1$ (darkness)

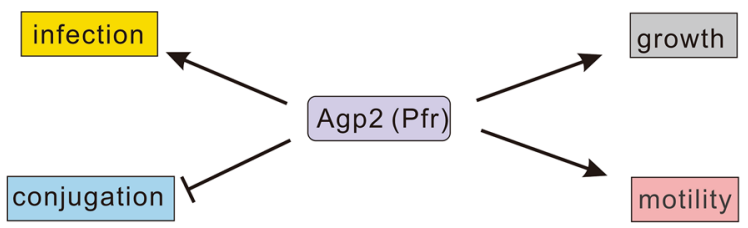

D

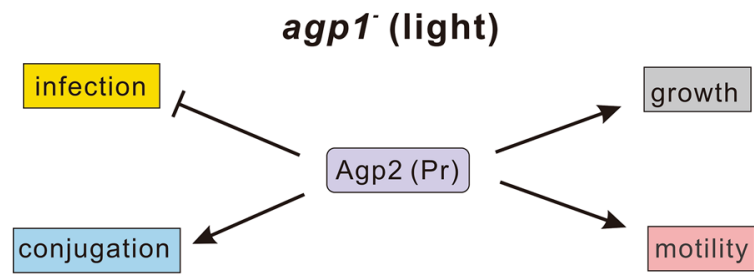

Fig. 6 Possible model of phytochrome responses in A. fabrum. The model includes effects on conjugation, infection, growth and motility. Four scenarios are shown: wild type (a and b) and mutant agpl $^{-}$(c and $\mathbf{d})$ in darkness $(\mathbf{a}, \mathbf{c})$ and light $(\mathbf{b}, \mathbf{d})$. The model is based on the interaction between Agp1 and Agp2 [39] by this interaction [39]. For a further detailed understanding of this paradox result, more mutant studies and molecular studies are required. A simple model for the action of both phytochromes on conjugation, infection, growth and motility and the reversion in the agpl-mutant is provided in Fig. 6.

Conjugation and plant infection have in common that both are connected with DNA transfer in which the type IV secretion system is involved. In both cases, plasmid DNA is nicked by a relaxase at a defined position. In both cases, a single strand is covalently bound to the protein, DNA is unwound in a helicase-catalyzed reaction and the single stranded DNA-protein complex transported into the target cell. Quite interestingly, 4 out of 4 conjugation proteins that were detected in the TMT assay were different between wild type and double knockout mutant. In case of the type IV secretion system, these are 3 out of 8. Regulation of protein concentration could be one mechanism in the phytochrome regulation of DNA transfer. In mRNA microarrays there was no evidence for light or phytochrome regulation of transcription of any of these proteins (data not shown). Therefore, we consider a regulation of protein degradation or protein stability as cause for these differences. Since the differences in protein abundance are not large, and there is no evidence for an impact of light on these protein levels, we consider however different mechanisms of signal transmission of light regulation. In conjugation and plant infection, dark action of phytochrome is reduced in the light. This pattern correlates with the histidine autokinase activity of Agp1 [7], but not with that of Agp2 [39]. Phosphotransfer is thus a possible initial signal transmission mechanism, but cannot be the only one. We have recently shown that Agp1 and Agp2 do interact in vitro [39]. Such an interaction could partially explain the co-action of both phytochromes that is found in most effects. Conjugation and plant infection could be mediated through a direct interaction of Agp1 and Agp2 with VirD2 and TraA, proteins that catalyze the first steps in DNA transfer processes of plant infection and conjugation, respectively, and modulate in a light dependent manner the nuclease activities of the enzymes.

Growth of A. fabrum (at ambient temperature) is phytochrome regulated in a light independent manner (Table 1). In the proteome studies, the majority of regulated proteins was found in mutant versus wild type comparisons, again indicating a light independent impact of phytochromes. "Light independent" and "dark active" are similar phenomena. A light independent effect is probably an effect where phytochrome is active both in the dark and in the light. Therefore, the list of proteins that were identified as phytochrome dependent but light independent can add up to the list of the other dark effects.

Specifically in the dark, phytochromes stimulate conjugation and infection, but inhibit growth and motility. 
Apparently, phytochromes function to direct metabolism toward synthesis of gene-transfer proteins, away from growth and motility. The increase of growth in phytochrome mutants could be a direct result of the inhibition of conjugation or infection.

The present study, together with earlier work, shows that both DNA transfer processes of $A$. fabrum, conjugation and plant infection, are controlled by light and by phytochromes. Based on microarray and proteome studies, we exclude differential gene activation as a first step of phytochrome regulation and propose a direct modulation of proteins that are involved in the first steps in DNA transfer processes.

Supplementary Information The online version contains supplementary material available at https://doi.org/10.1007/s00284-021-02526-5.

Acknowledgements We thank Nadja Wunsch for technical assistance.

Author Contributions PX, NK, TL conceptualization, writing original draft, NK TL writing final draft, YB performed motility assay, YB and TL analyzed these data, PX, YB, GR, EA, investigation, PX, YB, GR, EA, YM, TR, PS, TL data curation, TL supervision.

Funding Open Access funding enabled and organized by Projekt DEAL. The project was supported by DFG Grants LA 799/7-3 and KR 2034/1 to T.L and NK. P.S. was supported by the DFG: SFB1078B06, SFB1365-A03 and Germany's Excellence Strategy-EXC 311 2008/1 (UniSysCat) - 390540038 (Research Unit E). P.X., Y. B. and Y.M. were supported by the China Scholarship Council.

Data Availability All data are available, material upon request.

\section{Declarations}

Conflict of interest There are no conflict of interest.

Open Access This article is licensed under a Creative Commons Attribution 4.0 International License, which permits use, sharing, adaptation, distribution and reproduction in any medium or format, as long as you give appropriate credit to the original author(s) and the source, provide a link to the Creative Commons licence, and indicate if changes were made. The images or other third party material in this article are included in the article's Creative Commons licence, unless indicated otherwise in a credit line to the material. If material is not included in the article's Creative Commons licence and your intended use is not permitted by statutory regulation or exceeds the permitted use, you will need to obtain permission directly from the copyright holder. To view a copy of this licence, visit http://creativecommons.org/licenses/by/4.0/.

\section{References}

1. Tsuda K, Qi Y, Nguyen LV, Bethke G, Tsuda Y, Glazebrook J, Katagiri F (2012) An efficient Agrobacterium-mediated transient transformation of Arabidopsis. Plant J 69(4):713-719. https://doi. org/10.1111/j.1365-313X.2011.04819.x

2. Gelvin SB (2017) Integration of Agrobacterium T-DNA into the plant genome. Annu Rev Genet 51:195-217
3. Burkholder WH (1948) Bacteria as plant pathogens. Annu Rev Microbiol 2:389-412. https://doi.org/10.1146/annurev.mi.02. 100148.002133

4. Woolley JT, Stoller EW (1978) Light penetration and lightinduced seed germination in soil. Plant Physiol 61(4):597-600. https://doi.org/10.1104/pp.61.4.597

5. Lee HJ, Ha JH, Kim SG, Choi HK, Kim ZH, Han YJ, Kim JI, Oh Y, Fragoso V, Shin K, Hyeon T, Choi HG, Oh KH, Baldwin IT, Park CM (2016) Stem-piped light activates phytochrome B to trigger light responses in Arabidopsis thaliana roots. Sci Signal 9(452):ra106. https://doi.org/10.1126/scisignal.aaf6530

6. Kumar N, Pandey S, Bhattacharya A, Ahuja PS (2004) Do leaf surface characteristics affect Agrobacterium infection in tea [Camellia sinensis (L.) O Kuntze]? J Biosci 29(3):309-317

7. Lamparter T, Michael N, Mittmann F, Esteban B (2002) Phytochrome from Agrobacterium tumefaciens has unusual spectral properties and reveals an N-terminal chromophore attachment site. Proc Natl Acad Sci USA 99:11628-11633

8. Karniol B, Vierstra RD (2003) The pair of bacteriophytochromes from Agrobacterium tumefaciens are histidine kinases with opposing photobiological properties. Proc Natl Acad Sci USA 100:2807-2812

9. Mancinelli A (1994) The physiology of phytochrome action. In: Kendrick RE, Kronenberg GHM (eds) Photomorphogenesis in plants, 2nd edn. Kluwer Academic Publishers, Dordrecht, pp 211-269

10. Kendrick RE, Kronenberg GHM (1994) Photomorphogenesis in plants, 2nd edn. Kluwer Academic Publishers, Dordrecht

11. Fischer R (2008) Developmental biology. Sex and poison in the dark. Science 320(5882):1430-1431

12. Woitowich NC, Halavaty AS, Waltz P, Kupitz C, Valera J, Tracy G, Gallagher KD, Claesson E, Nakane T, Pandey S, Nelson G, Tanaka R, Nango E, Mizohata E, Owada S, Tono K, Joti Y, Nugent AC, Patel H, Mapara A, Hopkins J, Duong P, Bizhga D, Kovaleva SE, St Peter R, Hernandez CN, Ozarowski WB, RoyChowdhuri S, Yang JH, Edlund P, Takala H, Ihalainen J, Brayshaw J, Norwood T, Poudyal I, Fromme P, Spence JCH, Moffat K, Westenhoff S, Schmidt M, Stojkovic EA (2018) Structural basis for light control of cell development revealed by crystal structures of a myxobacterial phytochrome. IUCrJ 5:619-634. https://doi.org/10.1107/s2052252518010631

13. Moyano L, Carrau A, Petrocelli S, Kraiselburd I, Gärtner W, Orellano EG (2020) Bacteriophytochromes from Pseudomonas syringae pv. tomato DC3000 modulate the early stages of plant colonization during bacterial speck disease. Eur J Plant Pathol 156(3):695-712. https://doi.org/10.1007/s10658-019-01918-5

14. Oberpichler I, Molina I, Neubauer O, Lamparter T (2006) Phytochromes from Agrobacterium tumefaciens: difference spectroscopy with extracts of wild type and knockout mutants. FEBS Lett 580(2):437-442

15. Bai Y, Rottwinkel G, Feng J, Liu Y, Lamparter T (2016) Bacteriophytochromes control conjugation in Agrobacterium fabrum. J Photochem Photobiol B 161:192-199

16. Lamparter $\mathrm{T}$ (2006) A computational approach to discovering the functions of bacterial phytochromes by analysis of homolog distributions. BMC Bioinform 7:141

17. Lassalle F, Campillo T, Vial L, Baude J, Costechareyre D, Chapulliot D, Shams M, Abrouk D, Lavire C, Oger-Desfeux C, Hommais F, Gueguen L, Daubin V, Muller D, Nesme X (2011) Genomic species are ecological species as revealed by comparative genomics in Agrobacterium tumefaciens. Genome Biol Evol 3:762-781

18. Nultsch W (1968) Effect of redox systems on the motility and the phototactic reactions of Phormidium uncinatum. Arch Mikrobiol 63(4):295-320 
19. Vancanneyt G, Schmidt R, O’Conner-Sanchez A, Willmitzer L, Rocha-Sosa M (1990) Construction of an intron-containing marker gene: splicing of the intron in transgenic plants and its use in monitoring early events in Agrobacterium mediated plant transformation. Mol Gen Genet 220:245-250

20. Oberpichler I, Rosen R, Rasouly A, Vugman M, Ron EZ, Lamparter T (2008) Light affects motility and infectivity of Agrobacterium tumefaciens. Environ Microbiol 10(8):2020-2029

21. Henrichsen J (1983) Twitching motility. Annu Rev Microbiol 37:81-93. https://doi.org/10.1146/annurev.mi.37.100183.000501

22. Gelvin SB (2006) Agrobacterium transformation of Arabidopsis thaliana roots: a quantitative assay. Methods Mol Biol 343:105-113

23. Jefferson RA (1987) Assaying chimeric genes in plants: the GUS gene fusion system. Plant Mol Biol Rep 5:387-405

24. Blazquez M (2007) Quantitative GUS Activity Assay of Plant Extracts. CSH Protoc 2007:pdb prot4690. https://doi.org/10.1101/ pdb.prot4690

25. Chourey K, Jansson J, VerBerkmoes N, Shah M, Chavarria KL, Tom LM, Brodie EL, Hettich RL (2010) Direct cellular lysis/ protein extraction protocol for soil metaproteomics. J Proteome Res 9(12):6615-6622. https://doi.org/10.1021/pr100787q

26. Njimona I, Lamparter T (2011) Temperature effects on Agrobacterium phytochrome Agp1. PLoS ONE 6(10):e25977

27. Lamparter T, Zhang F, Graf D, Wesslowski J, Oberpichler I, Schünemann V, Krauß N, Scheerer P (2011) A prokaryotic (6-4) photolyase with a DMRL chromophore and an iron-sulfur cluster. Encyclopedia of inorganic and bioinorganic chemistry. Wiley, New York

28. Oberpichler I, Pierik AJ, Wesslowski J, Pokorny R, Rosen R, Vugman M, Zhang F, Neubauer O, Ron EZ, Batschauer A, Lamparter T (2011) A photolyase-like protein from Agrobacterium tumefaciens with an iron-sulfur cluster. PLoS ONE 6(10):e26775

29. Oberpichler I (2007) Photorezeptoren und lichteffekte in Agrobacterium tumefaciens. FU Berlin, Berlin

30. Zienicke B, Molina I, Glenz R, Singer P, Ehmer D, Escobar FV, Hildebrandt P, Diller R, Lamparter T (2013) Unusual spectral properties of bacteriophytochrome Agp2 result from a deprotonation of the chromophore in the red-absorbing form Pr. J Biol Chem 288(44):31738-31751

31. Pichler P, Kocher T, Holzmann J, Mazanek M, Taus T, Ammerer G, Mechtler K (2010) Peptide labeling with isobaric tags yields higher identification rates using iTRAQ 4-plex compared to TMT 6-plex and iTRAQ 8-plex on LTQ Orbitrap. Anal Chem 82(15):6549-6558. https://doi.org/10.1021/ac100890k

32. Ma LS, Hachani A, Lin JS, Filloux A, Lai EM (2014) Agrobacterium tumefaciens deploys a superfamily of type VI secretion DNase effectors as weapons for interbacterial competition in planta. Cell Host Microbe 16(1):94-104. https://doi.org/10.1016/j. chom.2014.06.002

33. Zambryski P (1988) Basic processes underlying \#Agrobacterium\#mediated DNA transfer to plant cells. Ann Rev Genet 22:1-30

34. Hopkins JA, Kiss JZ (2012) Phototropism and gravitropism in transgenic lines of Arabidopsis altered in the phytochrome pathway. Physiol Plant 145(3):461-473

35. Kendrick RE, Nagatani A (1991) Phytochrome mutants. Plant J 1(2):133-139

36. Liscum E, Hangarter RP (1993) Photomorphogenic mutants of Arabidopsis thaliana reveal activities of. Planta 191:214-221

37. Njimona I, Yang R, Lamparter T (2014) Temperature effects on bacterial phytochrome. PLoS ONE 9(10):109794

38. Yu Z, Armant O, Fischer R (2016) Fungi use the SakA (HogA) pathway for phytochrome-dependent light signalling. Nat Microbiol 1(5):1-7

39. Xue P, El Kurdi A, Kohler A, Ma H, Kaeser G, Ali A, Fischer R, Krauß N, Lamparter T (2019) Evidence for weak interaction between phytochromes Agp1 and Agp2 from Agrobacterium fabrum. FEBS Lett 593(9):926-941. https://doi.org/10.1002/18733468.13376

Publisher's Note Springer Nature remains neutral with regard to jurisdictional claims in published maps and institutional affiliations. 